Check for updates

Cite this: RSC Adv., 2017, 7, 33680

Received 30th May 2017

Accepted 27th June 2017

DOI: $10.1039 / \mathrm{c} 7 \mathrm{ra06027k}$

rsc.li/rsc-advances

\section{Suppression of degradation for lithium iron phosphate cylindrical batteries by nano silicon surface modification}

\author{
Wenyu Yang, ${ }^{\mathrm{ab}}$ Zhisheng Wang, ${ }^{\mathrm{ab}}$ Lei Chen, $^{\mathrm{ab}}$ Yue Chen, ${ }^{\mathrm{ab}}$ Lin Zhang, ${ }^{\mathrm{ab}}$ Yingbin Lin, ${ }^{\mathrm{ab}}$ \\ Jiaxin $\mathrm{Li}^{\mathrm{ab}}$ and Zhigao Huang (iD *ab
}

\begin{abstract}
Nano-scale silicon particles were successfully decorated uniformly on a $\mathrm{LiFePO}_{4} \mathrm{QC}$ electrode through utilization of spray technique. The electrochemical measured results indicate that the $\mathrm{Si}$ surface modification results in improved electrochemical performances for commercial 18650 cylindrical batteries, especially at elevated temperature, which is attributed to the fact that Si introduction can enable the $\mathrm{LiFePO}_{4}$ electrodes to suppress cylindrical battery degradation. Based on the analysis of structural characterization, it is revealed that the battery cathode with $\mathrm{Si}$ modification retains a better $\mathrm{LiFePO}_{4}$ phase and exhibits less $\mathrm{Li}^{+}$loss. In addition, the negative electrode of the battery contains a better graphite carbon structure and a thinner thickness of SEI film due to Si decoration. Furthermore, the related high-temperature aging and degradation mechanisms of the batteries were discussed.
\end{abstract}

\section{Introduction}

Recently, the commercial $\mathrm{LiFePO}_{4}$-based lithium-ion batteries (LFP-LIBs) have been widely applied in mobile phones, laptop computers and electric vehicles, because it demonstrates lots of advantages including environment friendliness, abundant source materials and high security. ${ }^{1-7}$ However, LFP-LIBs still suffer from the issue of significant capacity fading, especially at high temperature, due to possible catalytic effects of the metallic iron particles and the active lithium ions being intensively consumed to construct an interfacial film on the graphite electrodes. ${ }^{8,9}$ Thus, many useful strategies, such as carbon coating, metal nanoparticle attachment and surface modification of active materials or electrodes, have been developed to overcome these technical bottlenecks. Among them, surface modification is regarded as one of the most promising approaches for LFP-LIBs. ${ }^{10-12}$ The electrochemical performances of $\mathrm{LiNi}_{1 / 3} \mathrm{Co}_{1 / 3} \mathrm{Mn}_{1 / 3} \mathrm{O}_{2}$ were enhanced via employing atomic layer deposition to coat a solid-state electrolyte with an appropriate thickness directly onto a prefabricated electrode. ${ }^{10}$ Moreover, various metal oxides have been selected as a candidate material for directly coating electrode. ${ }^{11}$ Many semiconductor materials, especially including $\mathrm{Si}$ acted as an intermediate isolated layer were employed in the field of surface engineering, which can efficiently suppress transition cations

${ }^{a}$ College of Physics and Energy, Fujian Normal University, Fujian Provincial Key Laboratory of Quantum Manipulation and New Energy Materials, Fuzhou, 350117, China.E-mail: zghuang@fjnu.edu.cn

${ }^{b}$ Fujian Provincial Collaborative Innovation Center for Optoelectronic Semiconductors and Efficient Devices, Xiamen, 361005, China from being dissolved from the active material causing by the attacking of $\mathrm{HF}$ in the electrolyte. ${ }^{13,14}$

As a typical example, compared to pristine $\mathrm{LiFePO}_{4}$ electrodes, the electrodes decorated with nano-sized Si can display less coarsening degree, higher rate capability and better cycling performance, especially at elevated temperature..$^{15}$ Guo et al. ${ }^{9}$ have exhibited that the $\mathrm{LiFePO}_{4} /$ graphite soft-packed cell has noticeable capacity loss at high temperature even though several electrolyte additives have been added to greatly hold down $\mathrm{Fe}$ dissolution. It has been proposed that greatly consumption of active lithium results from continuous reformation/repairing of SEI layer, which was ascribed to SEI instability in electrolyte at elevated temperatures. ${ }^{16}$ In addition, the reports revealed that the degradation of LFP-LIBs is also leaded by the structural damage of active material resulting from the dissolution of $\mathrm{Fe}^{3+}$ into the electrolyte, impedance rise arising from the decrease of electrical conductivity for electrode sheet leaded by slack of contact between active particles, and lithium inventory loss associated with side reaction at electrode/electrolyte interface including the redox decomposition of the electrolyte, establishment of unstable solid electrolyte interface (SEI) films. ${ }^{17-19}$ Based on the preliminary understanding of aging mechanism for LFP-LIBs at high temperature, Si modification on the electrodes is an effective path to suppress the degradation of LFP and to obtain an excellent LIB performance.

Continuing with the above description, how to investigate the degradation of LFP materials and further to analysis the related aging mechanism is an eternal topic for the studies and application of LFP-LIBs. ${ }^{20,21}$ The phase transformations of $\mathrm{LiFePO}_{4}$ in $\mathrm{Li}^{+}$intercalation/deintercalation have been 
investigated by means of XRD. ${ }^{22}$ However, it is difficult to exactly provide information about the surface properties of material. Fortunately, Raman spectroscopy (RS) has ability to detect the surface phase change for active cathode material accurately. ${ }^{23,24}$ According to previous research results, both internal and external modes were used to investigate the phase changes. ${ }^{25-27}$ In addition, Kelvin Probe Force Microscopy (KPFM) has also been considered as a novel surface characterization technique to study the aging mechanism of battery material surface on nanoscale by measuring surface potential. ${ }^{28,29}$ The surface potential is generally the electronic work function (EWF) difference between the sample and the tip, which is sensitive to the structural and chemical changes for the surface chemical composition. It can effectively reflect the micro variation of the electronic structure, providing vital information about surface destruction. Thus, using effective analytical methods including MS and KPFM to discuss the above topic is useful and much needed.

However, most reports were based on the different types of button cells using very small amount of active materials, which may lead to deviation from the actual situation of the commercial LIBs. Thus, for commercial LFP-LIBs, it is critically urgent to realize the Si surface decoration on LFP electrodes by a simple route, and to further reveal their high-temperature aging mechanism via effective analytical methods. In this paper, Si modified LFP electrodes successfully prepared with the technique of ultrasonic spray, combined with the anodic graphite electrodes, have been assembled in commercial 18650 cylindrical batteries. Compared to pristine $\mathrm{LiFePO}_{4}$ electrodes, the 18650 cylindrical batteries with Si modification can deliver obviously better LIB performances at room temperature and elevated temperature. It can be concluded that silicon surface modification implements suppression of degeneration of lithium ion batteries. Eventually, the aging and degradation mechanisms of the batteries were discussed by using effective analytical methods, such as RS and KPFM.

\section{Experimental}

\section{$\mathrm{LiFePO}_{4} /$ graphite cylindrical battery preparation}

The positive electrodes were prepared by uniformly pasting a slurry consisting of $90 \mathrm{wt} \%$ active material (commercial $\mathrm{LiFePO}_{4}$ powder), $5 \mathrm{wt} \%$ Super-P and $5 \mathrm{wt} \%$ polyvinylidene fluoride (PVDF) dissolved in $N$-methyl-2-pyrrolidone on an aluminum foil. The negative electrodes were obtained by bonding the slurry mixed with commercial-grade graphite material, styrene butadiene rubber (SBR), carboxymethyl cellulose (CMC) and Super P onto a copper foil substrate. Silicon nanoparticles were uniformly deposited on the positive electrodes by a simple and novel spray technique, as seen in our previous work. ${ }^{15}$ On the process of spraying, the distance between nozzles and electrode sheet was controlled about $12 \mathrm{~cm}$. Meanwhile, the spraying flow rate was controlled as $2 \mathrm{ml}$ $\min ^{-1}$. The compaction of positive and negative electrodes was finished by adjusting the best thickness in the large rolled and pressed device (LDHY400-N45). Here, the ratio of active material mass of negative electrode to that of positive electrode was chosen to be 0.453 . Eventually, they were rolled together to make the battery core with a separator as isolating layer. Then this was packed into a cylindrical can and dried overnight at $85{ }^{\circ} \mathrm{C}$ under vacuum. The commercial electrolyte containing a lithium hexafluorophosphate $\left(\mathrm{LiPF}_{6}\right)$ salt in 1:1 ethyl carbonate (EC) and dimethyl carbonate (DMC) was injected into dried batteries in a glove box filled argon atmosphere. The fabricated batteries were conducted at $0.02 \mathrm{C}(1 \mathrm{C}=1500 \mathrm{~mA} \mathrm{~h})$ to build up a smooth SEI layer on the negative electrode surface. According to our previous report, ${ }^{15}$ the purchased commercial active materials of $\mathrm{LiFePO}_{4}$ and graphite can deliver the reversible capacities of $\sim 110$ and $\sim 290 \mathrm{~mA} \mathrm{~h} \mathrm{~g}^{-1}$ at $1 \mathrm{C}$ tested rate. As expected, the cycling capacity for the 18650 cylindrical batteries used in this work was designed to be $\sim 1400 \mathrm{~mA} \mathrm{~h} \mathrm{~g}^{-1}$ at $1 \mathrm{C}$ tested rate. Hereinafter, the batteries used pristine $\mathrm{LiFePO}_{4} @ \mathrm{C}$ and $\mathrm{Si}$ modification of $\mathrm{LiFePO}_{4} @ \mathrm{C} / \mathrm{Si}$ as cathodic materials were named as battery A and battery B, respectively.

\section{Electrochemical measurement for 18650 cylindrical batteries}

The cycle performances of batteries A and B were measured in the voltage range $2.5 \mathrm{~V}$ to $3.95 \mathrm{~V}$, under room temperature. After the two days storage in drying oven at $60{ }^{\circ} \mathrm{C}$, the cycle performances for batteries $\mathrm{A}$ and $\mathrm{B}$ were measured at $60{ }^{\circ} \mathrm{C}$ in the same voltage range. The batteries were charged to $3.95 \mathrm{~V}$ at $0.2 \mathrm{C}$ via galvanostatic mode, then constant voltage charging was conducted until the current was less than $0.02 \mathrm{C}(1 \mathrm{C}=1500 \mathrm{~mA}$ h). Hereafter, these were galvanostatically discharged to $2.5 \mathrm{~V}$ at 3C. Their rate performances of batteries A and B were conducted at room temperature. Their testing conditions for charging process were the same as the above. In the process of discharge, the batteries were discharged to $2.5 \mathrm{~V}$ at $0.5 \mathrm{C}, 1 \mathrm{C}, 2 \mathrm{C}$ and $3 \mathrm{C}$ at the conduction of constant current, respectively. In impedance measurement, the batteries $\mathrm{A}$ and $\mathrm{B}$ in fully discharge state down to $2.5 \mathrm{~V}$ in various cycles were recorded over the frequency range from $10 \mathrm{mHz}$ to $100 \mathrm{KHz}$ with an amplitude of $15 \mathrm{mV}$ on electrochemical workstation (CHI660C).

\section{Characterization of materials}

The cycled batteries A and B were disassembled in glove box at fully-discharged state. Then, the stripping of long anode and cathode strips were finished carefully, after batteries were unrolled. Subsequently, the anode and cathode were washed several time with pure dimethyl carbonate (DMC) to totally remove electrolyte and dried under vacuum. The morphologies of electrode samples were characterized by a scanning electron microscope (SEM, Hitachi SU8010), which equipped with energy dispersive X-ray spectroscopy (EDS) and elemental mapping facilities. The phases of electrode materials were characterized by an X-ray diffraction (XRD, Rigaku MiniFlex II) using $\mathrm{CuK}_{\alpha}$ radiation $(\lambda=0.15405 \mathrm{~nm})$ with a step of 8 degree per minute. The Raman spectra (RS) were carried out at room temperature by usage of HORIBA Jobin Yvon Evolution with laser excitation at $532 \mathrm{~nm}$. To avoid damage of electrode material surface, the laser power was adjusted below $5 \mathrm{~mW}$. The surface condition of the cycled electrodes was recorded through the X-ray photoelectron spectroscopy (XPS, Thermo Fisher 
ESCALAB 250Xi) using Al-K $\alpha(1486.6 \mathrm{eV})$ radiation as excitation source operated at $150 \mathrm{~W}$. Surface potential of samples were conducted with amplitude modulated Kelvin Probe Force Microscopy (KPFM, Dimension Icon). The value of the surface potential $\left(V_{\mathrm{SP}}\right)$ is described by the following equation:

$$
V_{\mathrm{SP}}=\frac{V_{\text {tip }}-V_{\text {sample }}}{q}
$$

where $V_{\text {tip }}$ and $V_{\text {sample }}$ stand for work functions of the tip and the sample, respectively, and $q$ represents the elementary charge. According to line scan mode on the sample, the surface height image was obtained in tipping mode with the amplitude of $0.5 \mathrm{~V}$ during the first pass. Hereafter, the tip was lifted and follows the surface topography at constant height of $160 \mathrm{~nm}$ in second pass. Through that, the surface potentials could be measured. In addition, the Pt/Ir coated cantilever (model SCMPIT- $\mathrm{V}_{2}$, resonance frequency $=75 \mathrm{kHz}$, force constant $=3 \mathrm{~N}$ $\mathrm{m}^{-1}$ ) was chosen to measure the surface potentials which was calibrated on the basis of sputtered Au thin film. It is in ambient conditions that calibration and measurements were carried.

\section{Results and discussion}

The cycle performances of $\mathrm{LiFePO}_{4} @ \mathrm{C}$ and $\mathrm{LiFePO}_{4} @ \mathrm{C} / \mathrm{Si}$ at high rate of $3 \mathrm{C}$ and under 25 and $60^{\circ} \mathrm{C}$ are displayed in Fig. 1a and b. From the Fig. 1a, the battery $\mathrm{B}$ can exhibit a stable reversible capacity of $1325 \mathrm{~mA} \mathrm{~h} \mathrm{~g}^{-1}$ tested at $3 \mathrm{C}$ rate after 100 cycles at room temperature, being obviously better than 1145 tested temperature to $60{ }^{\circ} \mathrm{C}$, it could be observed from Fig. $1 \mathrm{~b}$ that the capacities of both batteries exhibit evident capacity fade compared to $25{ }^{\circ} \mathrm{C}$, which is similar to the previous report. ${ }^{30,31}$
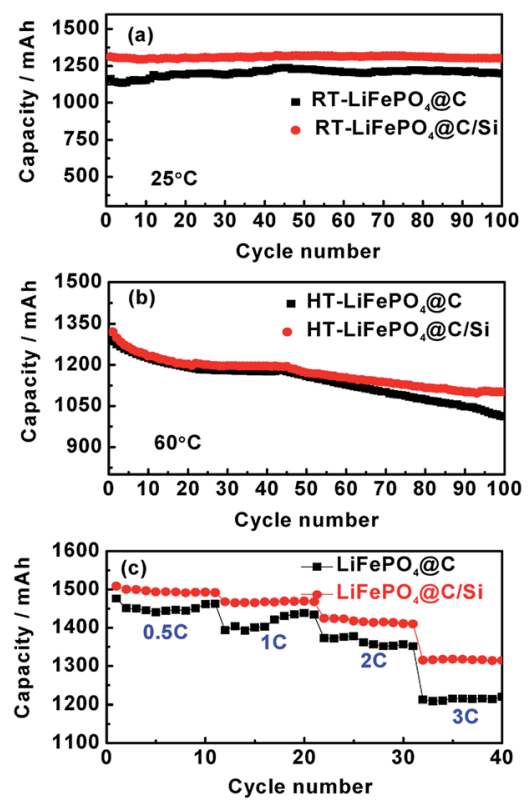

Fig. 1 Cycling performances of batteries $A$ and $B$ at $3 C$ between 2.5 and $3.95 \mathrm{~V}$, at room temperature (RT) of $25^{\circ} \mathrm{C}(\mathrm{a})$ and high temperature $(\mathrm{HT})$ of $60^{\circ} \mathrm{C}$ (b); (c) rate performances of batteries $\mathrm{A}$ and $\mathrm{B}$ at $0.5,1 \mathrm{C}$, $2 \mathrm{C}$ and $3 \mathrm{C}$ between 2.5 and $3.95 \mathrm{~V}$, at $25^{\circ} \mathrm{C}$.
Similarly, an reversible capacity of $1110 \mathrm{~mA} \mathrm{~h} \mathrm{~g}^{-1}$ for battery B is retained at 3C, while for the battery A only $1010 \mathrm{~mA} \mathrm{~h} \mathrm{~g}^{-1}$ is observed. This result reveals that Si modification does effectively suppress the degradation of cylindrical battery at elevated temperature. Fig. 1c shows the rate performances of cells A and B between 2.5 and $3.95 \mathrm{~V}$ at $25{ }^{\circ} \mathrm{C}$. From the figure, it is found that battery $\mathrm{B}$ has higher capacity and rate capability than those of battery A, which further confirms that the introduction of silicon nanoparticles is beneficial for the electrochemical performance improvement of 18650 cylindrical batteries. Similar rate performances of cells A and B were also observed at $60{ }^{\circ} \mathrm{C}$. Here, the content of Si on the electrode is about $2.45 \mathrm{at} \%$, which is verified by EDS. In addition, the discharging curves of the batteries A and B under different current density are shown in Fig. 2a and b, respectively. And the discharge plateaus voltage as a function of C-rate is shown in Fig. 2c. From the figures, it is observed that the batteries $\mathrm{A}$ and $\mathrm{B}$ have a comparatively flat discharging voltage plateau. However, the curves for battery A become shorter and lower than that of battery $\mathrm{B}$ with the increase of current density, indicating that the cell $\mathrm{B}$ with silicon modification during discharging process has much higher energy storage. Moreover, it can be found that the discharging plateaus voltage of battery $\mathrm{B}$ are higher than those of battery A, implying that battery B possesses less internal resistance due to the introduction of silicon. In order to illustrate the variation of internal resistance, both batteries A and B under various conditions after 100 cycles were conducted by EIS. Fig. $3 \mathrm{a}$ and $\mathrm{b}$ show the typical Nyquist plots for both batteries A and $\mathrm{B}$ respectively, which is consist of an inductive tail, a small loop, a large loop, and a straight line. Here, one of loops may become too small to be observed or maybe two loops have partly
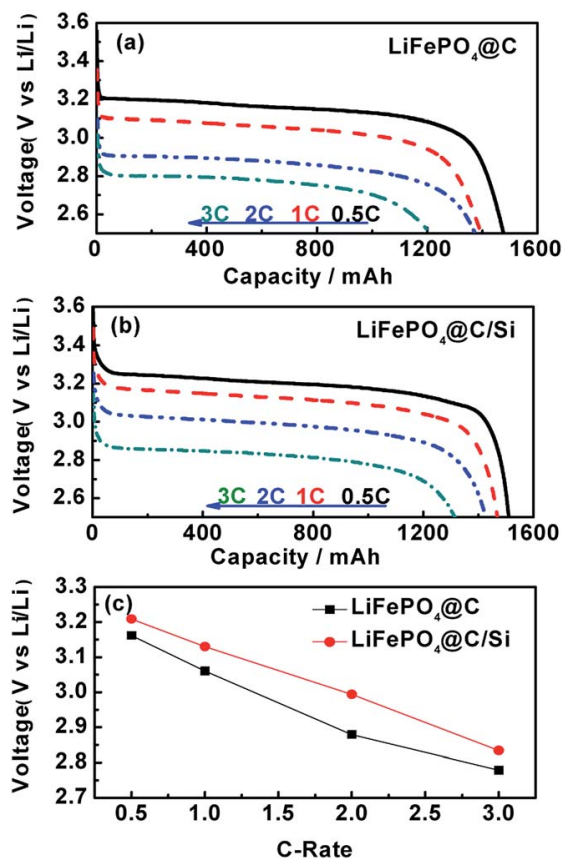

Fig. 2 The discharging curves of batteries $A(a)$ and $B(b)$ at $0.5,1 C, 2 C$ and $3 \mathrm{C}$ between 2.5 and $3.95 \mathrm{~V}$, respectively; (c) the discharge plateaus voltage as a function of $\mathrm{C}$-rate. 

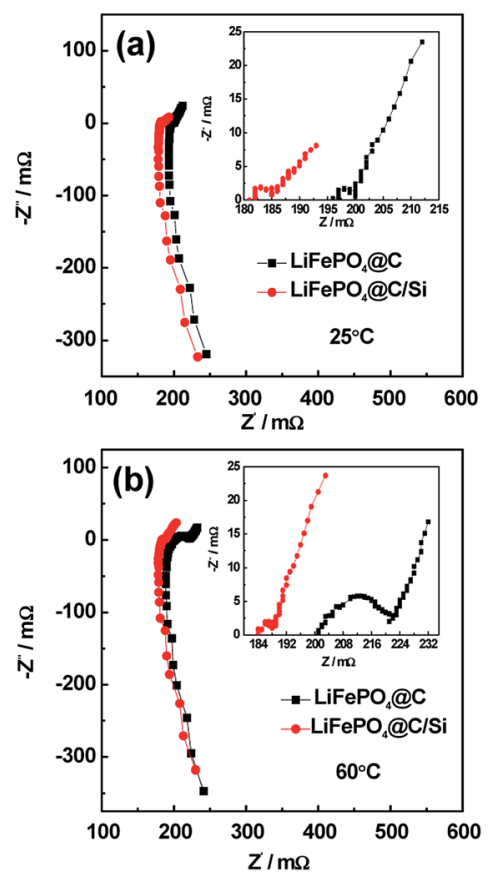

Fig. 3 The electrochemical impedance spectroscopy of batteries A and $\mathrm{B}$ at fully discharge state down to $2.5 \mathrm{~V}$ during 100 cycles (a) at $25^{\circ} \mathrm{C}$ and (b) $60^{\circ} \mathrm{C}$.

overlapped. The appearance of inductive tail can be attributed to the geometry effects and being neglected. ${ }^{32}$ The higher frequency loop is believed to be come from the SEI components on the surface of electrode and the others in the medium frequency is derived from the charge transfer and the double layer effect. ${ }^{33}$ The straight line is assigned to the $\mathrm{Li}^{+}$diffusion coefficient in a solid-phase electrode. As seen in Fig. 3a, the width of semicircle in the middle frequency for battery $\mathrm{A}$ is similar to those of battery B at $25^{\circ} \mathrm{C}$, which means that the total internal resistance of battery $\mathrm{A}$ is nearly equal to those of battery B. By fitting EIS date well, the $R_{\mathrm{ct}}$ values of charge transfer resistance were found to be $2.73 \mathrm{~m} \Omega$ and $2.98 \mathrm{~m} \Omega$ for batteries A and B. However, the total impedance for battery A is obviously larger than that of battery B after 100 cycles under high temperature, as demonstrated by the larger semicircle of EIS spectra for the former, shown in Fig. 3b. The date fitting results show that the $R_{\mathrm{ct}}$ values of batteries A and B is $27.5 \mathrm{~m} \Omega$ and 2.16 $\mathrm{m} \Omega$ at $60{ }^{\circ} \mathrm{C}$, respectively. It implies that the increase of internal impedance for battery is suppressed by the protection of silicon for surface of cathode electrode. This is consistent with the results of cycle performances at $60{ }^{\circ} \mathrm{C}$. As we know, the hightemperature LIB performance is an important indicator for practical application. Thus, the high-temperature aging and degradation mechanisms of the batteries were discussed in the following section.

To get more insight to the mechanism of Si modification suppression of capacity fading for the cycled 18650 cylindrical battery, the cycled battery A and B after 100 cycles at $60{ }^{\circ} \mathrm{C}$ were disassembled at fully discharge state. As found in Fig. 4, the three measured sites " 1 ", " 2 " and " 3 " on the anode and cathode electrodes for batteries A and B were chosen. Herein, the site " 1 "

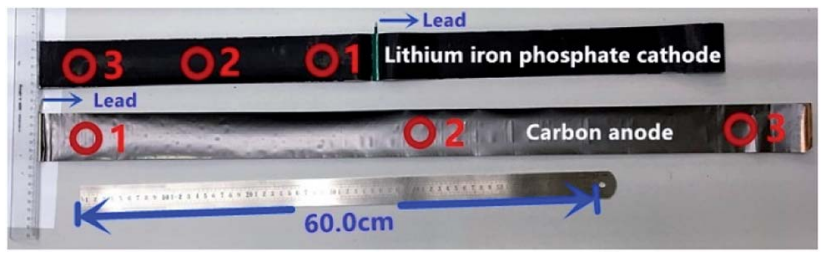

Fig. 4 The measured sites "1", "2" and " 3 " on the anode and cathode electrodes for 18650 battery; the site " 1 " on the cathode electrode is nearest the lead; the site " 3 " on the cathode electrode is the most far away from the lead; the site " 2 " is the middle between " 1 " and " 3 ".

is the most near to the lead. Correspondingly, Fig. 5a and $6 \mathrm{a}$ compared the SEM images of graphite anodes for both batteries. Compared to the morphology at site " 1 " for the battery A in Fig. 5a, SEM image for battery B in Fig. 6a displays smoother surface without visible physical damage. The compact and smooth coating layer for electrode means that the battery $\mathrm{B}$ has relatively low contact resistance, thus improving the electrochemical performance at $60^{\circ} \mathrm{C}$. From Fig. $5 \mathrm{c}$ and $6 \mathrm{c}$, it is also found that carbon, oxygen and phosphorus elements exist on the surface of anode except for iron element for both batteries. Here, it is suggested that oxygen comes from different organic and inorganic salts which are major components of SEI and phosphorus appearance comes likely from the reduction of $\mathrm{PF}_{6} \cdot{ }^{34}$ Furthermore, Fig. $5 \mathrm{~b}$ and $6 \mathrm{~b}$ show element mappings of Fe for batteries A and B, respectively. From the figure, it is observed that Fe element is distributed uniformly on the both anodic electrode surfaces, which reveals that the dissolution Fe from LFP active material was deposited on the graphite anode surface. Especially, as confirmed by EDS, in comparison with 0.33 at $\%$ Fe deposition on site " 1 " of graphite electrode of battery A, that of battery B presents less value of $\sim 0.17$ at $\%$, indicating that Si modification effectively avoids the damage of active materials by means of the dangling bonds of silicon absorbing $\mathrm{H}^{+}$. It is worth mention that $\mathrm{Fe}$ deposition could catalyze the SEI formation on the surface of anode. And SEI continuous growth and rearrangement on carbon surface consume active $\mathrm{Li}^{+}$simultaneously, which gives rise to the increase of the surface resistance. This is confirmed as a main reason to explain plenty of lithium loss during electrochemical

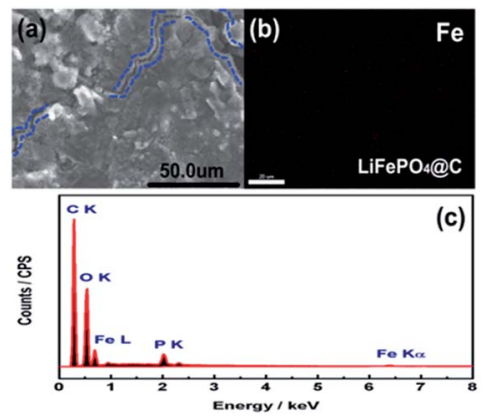

Fig. 5 (a) SEM images, (b) element mappings of $\mathrm{Fe}$, and (c) EDS spectrum of anode at site " 1 " for battery A after 100 cycles, at $3 C$ and $60{ }^{\circ} \mathrm{C}$. 


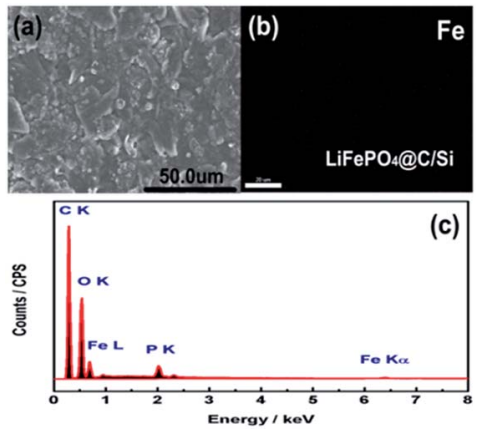

Fig. 6 (a) SEM images, (b) element mappings of Fe, and (c) EDS spectrum of anode at site " 1 " for battery B after 100 cycles, at $3 C$ and $60{ }^{\circ} \mathrm{C}$.

cycles. ${ }^{35}$ It is not difficult to explain that the battery B with less Fe deposition content on the surface of the anode electrode has the better electrochemical performances. More Fe deposition intensifies the formation of thicker SEI and leads to more irreversible capacity loss. Due to brittle nature of thick SEI, the trace of cracking of anode electrode surface observed from Fig. 5a could also illustrate the existence of thicker SEI, further explaining that an amount of Fe element distributed on the anode electrode surface is associated with much irreversible capacity loss. On the other hand, EDS spectra at the site " 2 " and " 3 " for anode electrodes of batteries A and B were also detected. It is found that the sites " 2 " and " 3 " for battery A have 0.28 at $\%$ and 0.03 at\% Fe contents. However, the sites " 2 " and " 3 " for battery B only own Fe contents of 0.04 at $\%$ and 0.0 at\%, respectively. It demonstrates that the degree of degradation on different surface site is quite different. Moreover, it is clearly observed that the Fe contents of different sites on the anode electrode of battery A are all much more than those for battery B. These SEM and EDS measured results verify that silicon nanoparticle surface modification could prevent the cathode active materials from attacking of $\mathrm{HF}$ in the electrolyte and subsequently alleviates active $\mathrm{Li}^{+}$loss.

To further explore the change of surface microstructure of graphite anode under high-temperature cycling, the aged electrodes were analyzed by XPS and Raman tests. Fig. 7a and b show C 1s XPS spectra of anode at site " 1 " for batteries A and B after 100 cycles at $3 \mathrm{C}$ and $60{ }^{\circ} \mathrm{C}$, respectively. According to the report, ${ }^{35}$ the C $1 \mathrm{~s}$ XPS spectra for both batteries were fitted well. The sharp peak around $284.5 \mathrm{eV}$ is assigned to $\mathrm{sp}^{2-}$ bonded graphite $(\mathrm{C}-\mathrm{C})$. At higher binding energy, the shoulder peak at $285.7 \mathrm{eV}$ belongs to typical carbon atoms as $\mathrm{C}-\mathrm{C}$ (or $\mathrm{C}-\mathrm{H}$ ). The peak located at $289.7 \mathrm{eV}$ is attributed to $\mathrm{CO}_{3}$ from SEI film, which is generally considered as $\left(\mathrm{CH}_{2} \mathrm{OCO}_{2} \mathrm{Li}\right)_{2}, \mathrm{ROCO}_{2} \mathrm{Li}$ and $\mathrm{Li}_{2} \mathrm{CO}_{3} \cdot{ }^{36}$ By calculation, we can get that the area ratios of the peaks at $284.5 \mathrm{eV}, 285.7 \mathrm{eV}$ and $289.7 \mathrm{eV}$ for battery A are $26.0 \%$, $44.2 \%, 29.8 \%$, respectively; while they for battery B are $33.9 \%$, $43.6 \%, 22.5 \%$, respectively. Through comparing, it can be found that relative peak area at $289.7 \mathrm{eV}$ for battery $\mathrm{A}$ is bigger than that of battery B, which means that battery A has thicker SEI film. Moreover, relative peak ratio at $284.5 \mathrm{eV}$ for battery $\mathrm{B}$ is larger than that of battery $\mathrm{A}$, which means that battery $\mathrm{B}$ retains
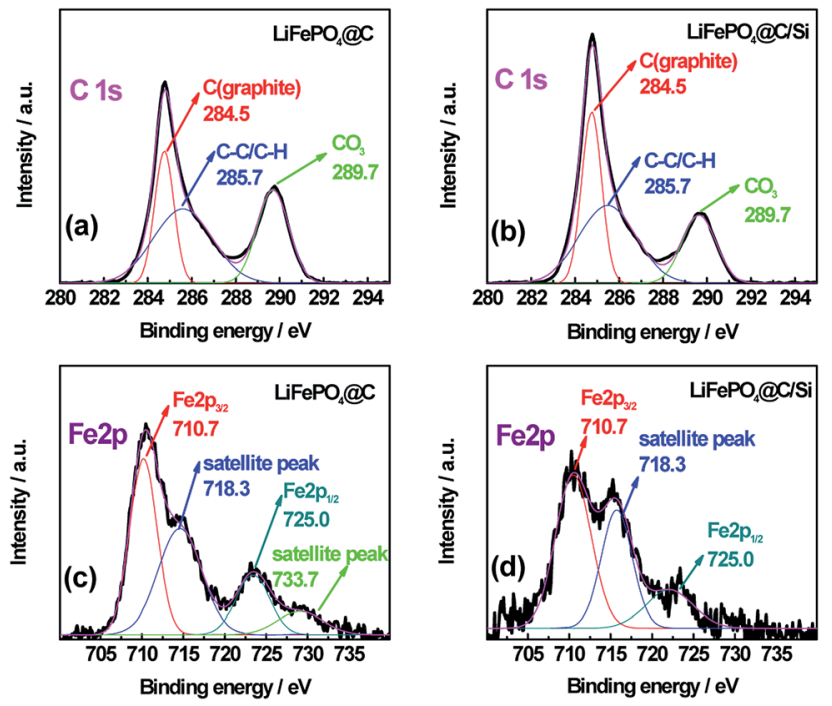

Fig. 7 The C 1s XPS spectra of anode at site "1" for batteries A (a) and B (b), and the Fe $2 p$ XPS spectra of anode at site "1" for batteries A (c) and $\mathrm{B}(\mathrm{d})$, after 100 cycles at $3 \mathrm{C}$ and $60^{\circ} \mathrm{C}$.

better graphite carbon structure. Furthermore, Fig. 7c and d show the Fe 2p XPS spectra for batteries A and B. The typical characteristic peaks at 710.7 and $725 \mathrm{eV}$ referring to $\mathrm{Fe} 2 \mathrm{p}_{3 / 2}$ and Fe $2 \mathrm{p}_{1 / 2}$, indicated the appearance of iron oxide on the surface of the anode for both batteries. ${ }^{37,38}$ Especially, the presence of satellite peak at about $718.3 \mathrm{eV}$ further confirms the existence of $\mathrm{Fe}_{2} \mathrm{O}_{3}$ on the surface of the anode. ${ }^{39}$ Moreover, from the XPS spectra, the contents of Fe element deposited on both graphite anodes for batteries A and B are found to be 1.19 at\% and 0.76 at\%, which is consistent with the results from EDS. It also demonstrates that the more Fe deposition intensifies indeed the formation of thicker SEI, which leads to more irreversible capacity fading. ${ }^{40}$ Zheng et al. ${ }^{36}$ proposed that the decomposition production of $\mathrm{LiPF}_{6}$ reacting with amounts of protic impurities can initiate an autocatalytic decomposition of electrolyte components, which causes metal ion dissolution, damage of the SEI on the carbon anode, and final capacity decay of battery. When $\mathrm{Si}$ is introduced on the surface cathode as a physical isolating layer, the decomposition speed of electrolyte components is slowed down and the destruction degree of cathode material is alleviated since the HF could not easily react with the cathode material. Fig. 8 shows Raman spectra for site " 1 " of both graphite electrodes after test and fresh graphite electrode for comparison, respectively. Herein, the relative intensity ratios between $\mathrm{D}$ and $\mathrm{G}$ peaks are associated with the disorder degree in carbon structure. ${ }^{41,42}$ It is found that the $I_{\mathrm{D}} / I_{\mathrm{G}}$ values for batteries A and B are increased drastically after tested at $60{ }^{\circ} \mathrm{C}$ for 100 cycles, implying that a large disorder degree was induced on the both graphite anode surface. Noticeably, compared to battery B, battery A with larger value of 0.834 for $I_{\mathrm{D}} /$ $I_{\mathrm{G}}$, suffers from obvious capacity loss, which is attributed to the severe destruction and reformation of SEI layer happening on the anode surface resulting in great active lithium consumption. Thus, combined the varied results in Fig. 5a and 6a, the compact and smooth anode for battery B has a thinner SEI film 


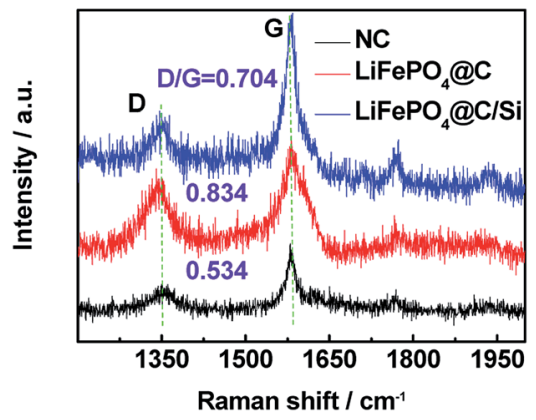

Fig. 8 Raman spectra for site "1" of anode electrodes for $\mathrm{LiFePO}_{4} \mathrm{QC}$ and LiFePO ${ }_{4} \mathrm{QC} / \mathrm{Si}$ after 100 cycles, at $3 \mathrm{C}$ and $60^{\circ} \mathrm{C}$; Raman spectrum of not-charged carbon (raw anode material, named as NC) was added.

and less Fe element deposition on the graphite surface than those of battery A, being responsible for the improved LIB performance.

In addition to the analysis for the graphite anode, the XRD and Raman have been used to analysis the LFP cathodes. The data detected from sites of " 1 ", " 2 " and " 3 " for XRD and Raman results were shown in Fig. 9 and 10, respectively. As displayed in Fig. 9a and b, almost diffraction peaks are indexed to orthorhombic olivine LFP (JCPDS no. 40-1499). From figures, two diffraction peaks around $18^{\circ}$ and $31^{\circ}$ are assigned to the phase of $\mathrm{FePO}_{4}$. The existence of $\mathrm{FePO}_{4}$ reveals that some $\mathrm{Li}^{+}$released from LFP phase were consumed by the formation of SEI layer on the anode surface, which leads to the decrease of reversible
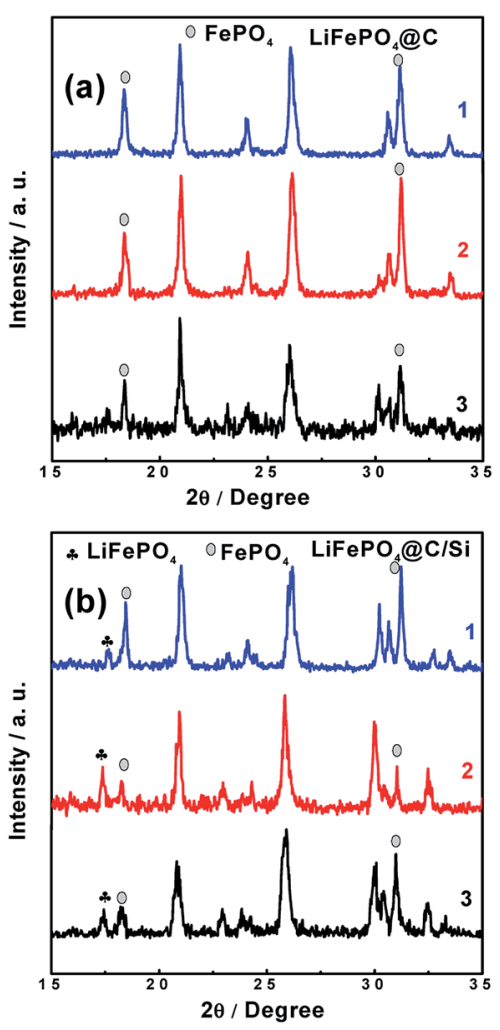

Fig. 9 XRD patterns of cathode surfaces at sites "1", "2" and "3" for (a) battery $\mathrm{A}$, (b) battery $\mathrm{B}$ after 100 cycles, at $3 \mathrm{C}$ and $60^{\circ} \mathrm{C}$.
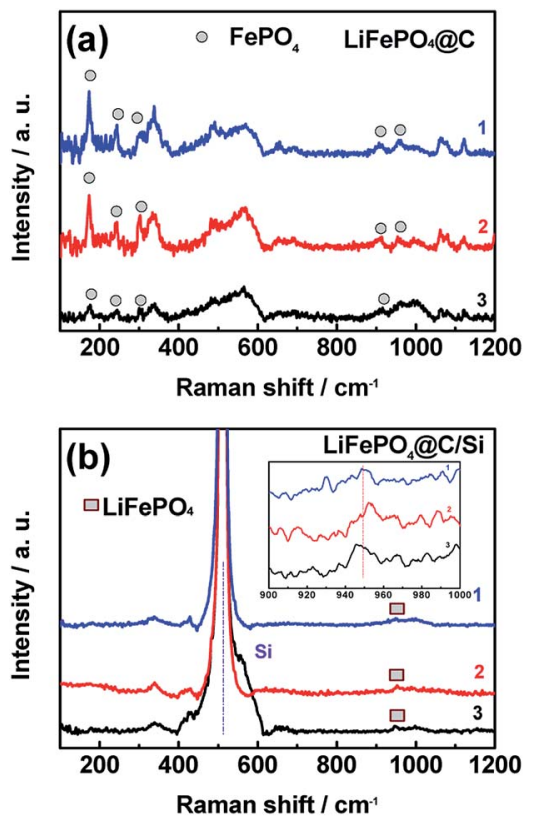

Fig. 10 The Raman spectra of cathode surfaces at sites "1", "2" and "3" for (a) battery $A$, (b) battery $B$ after 100 cycles, at $3 \mathrm{C}$ and $60^{\circ} \mathrm{C}$.

capacity of the battery. It is worth mention that the peak at $17.1^{\circ}$ corresponding to LFP phase (denoted with plum blossom) is sensitive with the extraction of $\mathrm{Li}^{+}$. Especially, the peak at $17.1^{\circ}$ belong to LFP phase on the site " 1 " for Si modified electrode remains, indicating that battery $\mathrm{B}$ has the lower loss of capacity, which is associated with relative improved LIB performances at elevated temperature. In other words, battery $\mathrm{B}$ possesses the lower intensity of $\mathrm{FePO}_{4}$ phase, demonstrating that battery $\mathrm{B}$ encounters a small degree of $\mathrm{Li}^{+}$consumption. Meanwhile, the other XRD results detected from sites " 2 " and " 3 " also support the above conclusion of site " 1 ". Comparing these three sites, different intensity of $\mathrm{FePO}_{4}$ observed in different site displayed that the different site experiences different $\mathrm{Li}^{+}$consumption, which also affected by the electrode temperature during cycling. Fig. 10a and b show the Raman spectra tested at those three sites from cathodes of both batteries after 100 cycles at $60^{\circ} \mathrm{C}$. At the sites " 1 ", " 2 " and " 3 " of cathode electrode for battery B, there still exist the scatting peaks near $953 \mathrm{~cm}^{-1}$, which is ascribe to the $\mathrm{A}_{\mathrm{g}}$ mode of $v_{1}$ in the internal modes of $\mathrm{LiFePO}_{4}$. This means that the surface of cathode electrode with silicon surface modification retains largely the structure of $\mathrm{PO}_{4}{ }^{3-}$. On the contrary, as seen in Fig. 10b, the peak at $953 \mathrm{~cm}^{-1}$ disappears while the two weak peaks at 908 and $959 \mathrm{~cm}^{-1}$ belong to the internal modes of $\mathrm{FePO}_{4}$ are observed for the cathode electrode of battery A. Meanwhile, the other three peaks around $174 \mathrm{~cm}^{-1}, 244 \mathrm{~cm}^{-1}, 305 \mathrm{~cm}^{-1}$ corresponding to characteristic one for the external modes of $\mathrm{FePO}_{4}$ were found. The appearance of the above three peaks means a phase change from $\mathrm{LiFePO}_{4}$ to $\mathrm{FePO}_{4}$ due to an amount of lithium-ion loss during high rate at elevated temperature. It reveals that silicon nanoparticle modification supports effective protection for the surface of cathode electrode of the battery, and suppressing effectively the consumption of lithium-ion. 
As we know, KPFM is a novel surface characterization technique to study the aging mechanism of battery material surface on nanoscale by measuring surface potential. Fig. 11 shows the surface height maps of site " 1 " of cathode for batteries A and B, respectively. From the figure, it is obviously observed that nanoscale silicon particles are still remained on the surface to hinder active material from being attacking even though experienced various cycles under elevated temperature. Within each surface potential map for site " 1 " of cathodes of batteries A and B, there exist no large difference in the contrast, as shown in Fig. 11c and $d$. However, their surface potentials and work functions have evident different. Fig. 12 shows the work function distribution curves of fresh $\mathrm{LiFePO}_{4} @ \mathrm{C}$, the aged $\mathrm{LiFePO}_{4} @ \mathrm{C}$ and $\mathrm{LiFePO}_{4} @ \mathrm{C} / \mathrm{Si}$. From the figure, one notices that the aged $\mathrm{LiFePO}_{4} @ \mathrm{C}$ possesses larger work function and wider full width at half maximum (FWHM), which should be attributed to the increase of $\mathrm{FePO}_{4}$ phase on the surface of cathode due to the more loss of lithium ion during the battery aging. These results demonstrate again that Si modification effectively suppresses the consumption of $\mathrm{Li}^{+}$due to on account of $\mathrm{Li}$ ions possessing the larger diffusion coefficient and less activation energy. ${ }^{43}$

As is well known, the capacity fading of lithium-ion batteries mainly result from the irreversible side reactions between electrode interface and electrolyte in the electrochemical system. In view of the potentials of the two electrodes, it is more possible that these side reactions occur on the negative surface. As a result, a complicated SEI containing inorganic and organic Li salt components deposits on the anode surface, which plays an important role in allowing Li ion to pass and efficiently preventing reductive decomposition of the electrolyte components. ${ }^{44}$ However, in practice, the stability and compactness of SEI is almost depending on either its chemical or physical properties. ${ }^{45}$ Especially when a certain amount of the Fe dissolution from lithium iron phosphate was electroreduced on the anode surface, it could catalyze the formation of the roughness SEI layer. Taking account for instability of SEI, especially solubility at elevated temperature, a continuous development and rearrangement of the SEI film is carrying on during repeated (a)

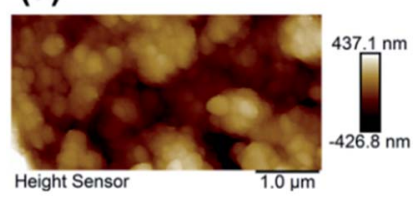

(c)

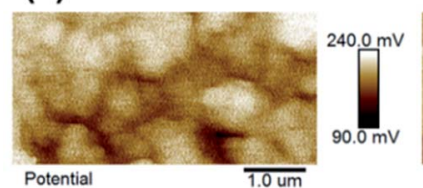

Fig. 11 The surface height maps at site "1" of the cathodes for $\mathrm{LiFePO}_{4} \mathrm{QC}$ (a) and $\mathrm{LiFePO}_{4} @ \mathrm{aC} / \mathrm{Si}(\mathrm{b})$ and the surface potential maps of $\mathrm{LiFePO}_{4} \mathrm{@C}$ (c) and $\mathrm{LiFePO}_{4} \mathrm{aC} / \mathrm{Si}$ (d), respectively. Here, the $\mathrm{LiFePO}_{4} \mathrm{@C}$ and $\mathrm{LiFePO}_{4} \mathrm{aC} / \mathrm{Si}$ were operated with 100 cycles, at $3 \mathrm{C}$ and $60^{\circ} \mathrm{C}$.

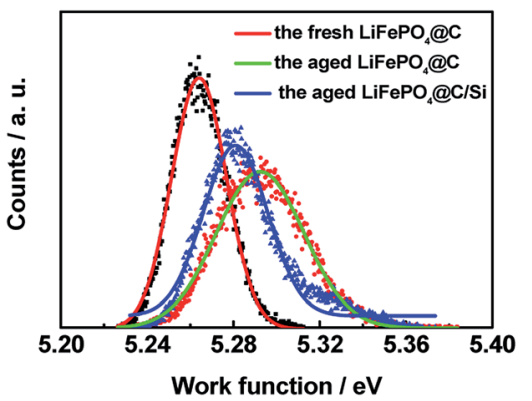

Fig. 12 The work function distribution curves of the cathodes for fresh $\mathrm{LiFePO}_{4} \mathrm{OC}$, batteries $\mathrm{A}$ and $\mathrm{B}$ after 100 cycles, at $3 \mathrm{C}$ and $60^{\circ} \mathrm{C}$.

electro-chemical cycles, which consumes more active lithiumion leading to loss of capacity. To explain the growth and rearrangement of SEI film on surface of anode under repeated electro-chemical cycles, three different mechanisms have been proposed by Tan et al. ${ }^{16}$ Combining the catalysis of Fe for the formation of SEI and a continuous development and rearrangement of SEI, it is not difficult to understand for evident capacity loss of battery A, especially at elevated temperature. From another perspective, the observation of relative more $\mathrm{Fe}$ element distribution on the surface of anode electrode of battery A means that cathode active material drastically suffer from the destruction of $\mathrm{HF}$ in the electrolyte. It is responsible for the capacity fading for battery cycled at high temperature. On the basic of the above discussion, it is proposed that silicon surface modification implements suppression of degradation of 18650 battery with $\mathrm{LiFePO}_{4}$ cathode material. Meanwhile, it improves also the rate, cycling performances of the battery at high discharge rate, especially at elevated temperature.

\section{Conclusions}

In summary, Si modified LFP electrodes successfully prepared with the technique of ultrasonic spray, combined with the anodic graphite electrodes, have been assembled in commercial 18650 cylindrical batteries and used to investigate their aging mechanism for LFP. Both 18650 cylindrical batteries were evaluated by cycling test and EIS, and their electrodes were characterized by EDS, SEM, XPS, XRD, Raman spectrum and Kelvin probe force microscopy, respectively. Compared with the batteries without Si modification, the results confirmed that, (a) the battery with modification contains better graphite carbon structure, less deposited $\mathrm{Fe}_{2} \mathrm{O}_{3}$ and thinner thickness of SEI film; (b) the cathode with $\mathrm{Si}$ modification remains better $\mathrm{LiFePO}_{4}$ phase, less $\mathrm{Li}^{+}$loss and integrity of structure. Therefore, Si modification implements suppression of degeneration of LIBs at high temperature.

\section{Acknowledgements}

We acknowledge the financial support by the Natural Science Foundations of China (No. 61574037, 21203025, 11344008, 11204038), Science and Technology Major Projects of Fujian Province (2013HZ0003), Project of Fujian Development and 
Reform Commission (2013-577), Educational Department of Fujian Province, China (JB14029). The authors gratefully acknowledge She-huang $\mathrm{Wu}$ for valuable discussions.

\section{Notes and references}

1 J. Vetter, P. Novak, M. R. Wagner, C. Veit, K. C. Moller, J. O. Besenhard, M. Winter, M. Wohlfahrt-Mehrens, C. Vogler and A. Hammouche, J. Power Sources, 2005, 147, 269-281.

2 M. Broussely, P. Biensan, F. Bonhomme, P. Blanchard, S. Herreyre, K. Nechev and R. J. Staniewicz, J. Power Sources, 2005, 146, 90-96.

3 R. F. Nelson, J. Power Sources, 2000, 91, 2-26.

4 K. Smith and C. Y. Wang, J. Power Sources, 2006, 160, 662673.

5 E. M. Krieger, J. Cannarella and C. B. Arnold, Energy, 2013, 60, 492-500.

6 J. Kang, F. Yan, P. Zhang and C. Du, Energy, 2014, 70, 618625.

7 M. Xu, Z. Q. Zhang, X. Wang, L. Jia and L. X. Yang, Energy, 2015, 80, 303-317.

8 D. J. Li, D. Dandslevelilov, L. Gao, Y. Yang and P. H. L. Notten, Electrochim. Acta, 2016, 210, 445-455.

9 Z. J. Guo and Z. L. Chen, J. Electroanal. Chem., 2015, 754, 148153.

10 X. F. Li, J. Liu, M. NorouziBanis, A. Lushington, R. Y. Li, M. Cai and X. L. Sun, Energy Environ. Sci., 2014, 7, 768-778.

11 X. F. Li, J. Liu, X. B. Meng, Y. J. Tang, M. NorouziBanis, J. L. Yang, Y. H. Hu, R. Y. Li, M. Cai and X. L. Sun, J. Power Sources, 2014, 247, 57-69.

12 B. Yan, X. F. Li, Z. M. Bai, Y. Zhao, L. Dong, X. S. Song, D. J. Li, C. Langford and X. L. Sun, Nano Energy, 2016, 24, 32-44.

13 X. Y. Dai, A. J. Zhou, J. Xu, B. Yang, L. P. Wang and J. Z. Li, J. Power Sources, 2015, 298, 114-122.

14 Q. Hao, C. X. Xu, S. Z. Jia and X. Y. Zhao, Electrochim. Acta, 2013, 113, 439-445.

15 W. Y. Yang, Z. Y. Zhuang, X. Chen, M. Z. Zou, G. Y. Zhao, Q. Feng, J. X. Li, Y. B. Lin and Z. G. Huang, Appl. Surf. Sci., 2015, 359, 875-882.

16 L. Tan, L. Zhang, Q. N. Sun, M. Shen, Q. T. Qu and H. H. Zheng, Electrochim. Acta, 2013, 111, 802-808.

17 N. Dupre, J. F. Martin, J. Degryse, V. Fernandez, P. Soudan and D. Guyomard, J. Power Sources, 2010, 195, 7415-7425.

18 M. Safari and C. Delacourt, J. Electrochem. Soc., 2011, 158, A1123-A1135.

19 K. Kumaresan, Q. Z. Guo, P. Ramadass and R. E. White, J. Power Sources, 2006, 158, 679-688.

20 B. Kang and G. Ceder, Nature, 2009, 458, 190-193.

21 K. Sun and S. J. Dillon, Electrochem. Commun., 2011, 13, 200202.

22 Y. Bai, Y. F. Yin, J. M. Yang, C. B. Qing and W. F. Zhang, J. Raman Spectrosc., 2011, 42, 831-838.
23 C. M. Burba, J. M. Palmer and B. S. Holinsworth, J. Raman Spectrosc., 2009, 40, 225-228.

24 B. C. Burba and R. Frech, J. Electrochem. Soc., 2004, 151, A1032-A1038.

25 J. Wu, G. K. P. Dathar, C. W. Sun, M. G. Theivanayagam, D. Applestone, A. G. Dylla, A. Manthiram, G. Henkelman, J. B. Goodenough and K. J. Stevenson, Nanotechnology, 2013, 24, 424009.

26 D. Gouveia, V. Lemos, J. De Paiva, A. Souza Filho, J. Mendes Filho, S. Lala, L. Montoro and J. Rosolen, Phys. Rev. B: Condens. Matter Mater. Phys., 2005, 72, 024105.

27 K. Xu, S. Zhang and T. R. Jow, Electrochem. Solid-State Lett., 2003, 6, A117-A120.

28 S. C. Nagpure, B. Bhushan and S. S. Babu, J. Power Sources, 2011, 196, 1508-1512.

29 S. Y. Luchkin, H. Y. Amanieu, D. Rosato and A. L. Kholkin, J. Power Sources, 2014, 268, 887-894.

30 K. Amine, J. Liu and I. Belharouak, Electrochem. Commun., 2005, 7, 669-673.

31 J. Shim, R. Kostecki, T. Richardson, X. Song and K. A. Striebel, J. Power Sources, 2002, 112(1), 222-230.

32 G. Nagasubramanian, J. Power Sources, 2000, 87, 226-229.

33 Y. D. Liu and J. Xie, J. Electrochem. Soc., 2015, 162, 22082217.

34 M. Dubarry and B. Y. Liaw, J. Power Sources, 2009, 194, 541549.

35 P. Verma, P. Maire and P. Novak, Electrochim. Acta, 2010, 55, 6332-6341.

36 L. P. Zheng, H. Zhang, P. F. Cheng, Q. Ma, J. J. Liu, J. Nie, W. F. Feng and Z. B. Zhou, Electrochim. Acta, 2016, 196, 169-188.

37 X. Zhu, X. Y. Song, X. L. Ma and G. Q. Ning, ACS Appl. Mater. Interfaces, 2014, 6, 7189-7197.

38 Y. Huang, Z. X. Lin, M. B. Zheng, T. H. Wang, J. Z. Yang, F. S. Yuan, X. Y. Lu, L. Liu and D. P. Sun, J. Power Sources, 2016, 307, 649-656.

39 T. Fujii, F. De Groot, G. Sawatzky, F. Voogt, T. Hibma and K. Okada, Phys. Rev. B: Condens. Matter Mater. Phys., 2001, 59, 3195-3202.

40 H. S. Song, Z. Cao, X. Chen, H. Lu, M. Jia, Z. A. Zhang, Y. Q. Lai, J. Li and Y. X. Liu, J. Solid State Electrochem., 2013, 17, 599-605.

41 R. Saito, T. Takeya and T. Kimura, Phys. Rev. B: Condens. Matter Mater. Phys., 1998, 57, 4145-4153.

42 V. A. Sethuraman, L. J. Hardwick, V. Srinivasan and R. Kostecki, J. Power Sources, 2010, 195, 3655-3660.

43 W. Y. Yang, M. Z. Zou, G. Y. Zhao, Z. S. Hong, Q. Feng, J. X. Li, Y. B. Lin and Z. G. Huang, Solid State Ionics, 2016, 292, 103109.

44 K. Tasaki, A. Goldberg, J. J. Lian, M. Walker, A. Timmons and S. J. Harris, J. Electrochem. Soc., 2009, 156(12), A1019-A1027. 45 L. Castro, R. Deryvère, J. B. Ledeuil, J. Bréger, C. Tessier and D. Gonbeau, J. Electrochem. Soc., 2012, 159(4), A357-A363. 